\title{
El lado colombiano de la frontera colombo-brasilera. Una aproximación desde la categoría de área sin ley ${ }^{1}$
}

\section{The Colombian side of the Colombian-Brazilian border. An approach using the category of lawless area}

\author{
Luis Fernando Trejos Rosero*
}

Resumen

En este trabajo se realiza una aproximación desde la categoría de área sin ley, a la compleja situación de seguridad generada por los crecientes vínculos de la criminalidad local con redes del crimen organizado transnacional en el lado colombiano de la frontera colombo-brasilera. El establecimiento permanente de actores armados ilegales en este espacio fronterizo se debe en gran medida a la ausencia y débil presencia del Estado colombiano en sus periferias. El abordaje metodológico es de tipo bibliográfico y descriptivo.

Palabras clave: Estado fallido, frontera, área sin ley, guerrilla, narcotráfico.

\begin{abstract}
This study uses the category of lawless areas as an approach to the complex security situation resulting from increasing ties between localized criminality and transnational organized crime networks on the Colombian side of the Colombian-Brazilian border. The permanent presence of illegal armed actors in this border area is largely caused by the absence and weak presence of the Colombian State at its margins. The methodology used is both bibliographic and descriptive. Keywords: Failed State, border, lawless area, guerrilla, drug trade.
\end{abstract}

Recibido: 26 de diciembre de 2013.

Aprobado: 22 de octubre de 2014.

${ }^{1}$ Este trabajo es fruto de la investigación "La diplomacia de tres actores no estatales colombianos. Insurgencia, sociedad civil y gobiernos locales en el escenario internacional”, xII Convocatoria Interna de Investigación: Modalidad Agendas de I+D+I, Universidad del Norte.

* Universidad del Norte, Departamento de Ciencia Política y Relaciones Internacionales, Instituto de Altos Estudios de América Latina y el Caribe. Barranquilla, Colombia. Dirección: Universidad del Norte, kilómetro 5, vía a Puerto Colombia, Barranquilla, Atlántico, Colombia.Correo electrónico: trejosl@uninorte.edu.co 
Luis Fernando Trejos Rosero / El lado colombiano de la frontera colombo-brasilera

\section{Las áreas sin ley}

Las áreas sin ley o áreas marrones, son definidas por O'Donnell (2004), Bartolomé (2003), Cirino y Elizondo (2003) y Cirino (2002) como aquellos espacios en que actores no estatales vinculados a prácticas y redes ilegales locales e internacionales acumulan tantos recursos e influencia que sobrepasan a las instituciones del Estado, ya sea por ausencia total del Estado o por su débil presencia. En este sentido, Wanderley (2000) sostiene que en estas zonas se presenta una "ingobernabilidad hobbesiana", entendida como una ruptura sostenida del tejido social en el marco de una violencia y criminalidad permanente en el tiempo, en lugares en que la autoridad estatal no cuenta con los recursos para imponerse de manera efectiva, por lo cual, el cuidado del orden público y la seguridad colectiva son inciertos. Al respecto, Cirino y Elizondo (2003) plantean tres causas que posibilitan la aparición de las áreas sin ley:

1. Políticas. Instituciones estatales débiles, lo que se traduce en una incapacidad para mantener el monopolio legítimo de la violencia y altos niveles de corrupción de los agentes estatales.

2. Político-geográfica. Las zonas de frontera, por su distancia de los centros productivos, no han sido conectadas con estos centros, además de su difícil acceso por la presencia de ciertas condiciones geográficas, como la espesa vegetación selvática y la ausencia de infraestructura vial o comunicacional, que las hacen espacios propicios para el establecimiento de organizaciones ilegales ligadas al crimen internacional.

3. Socio-económicas. La instalación de zonas francas, en estas áreas, amplía las capacidades operativas de los actores no estatales (ilegales), ya que gracias a las ganancias económicas producidas por actividades ilícitas como el contrabando, el narcotráfico y el lavado de activos, obtienen los recursos necesarios para el sostenimiento de sus actividades. Como ejemplo pueden tomarse los casos de la Ciudad de Maicao en la Guajira Colombiana, Colón en Panamá e Iquique en el norte de Chile.

En la literatura relativamente reciente, se ha hablado de las "áreas grises", enmarcadas dentro del posmodernismo, superando las teorías 
Estado-céntricas de las relaciones internacionales, al proponer una nueva cartografía del escenario internacional ya que tiene como telón de fondo la seguridad internacional. Este concepto presenta poca claridad en su definición y autores como Lupsha (1993), Guéhenno (1999) y Maisonneuve (1998) lo utilizan para describir espacios en los que se presentan ciertas condiciones muy similares a las que se encuentran en las áreas sin ley, tales como presencia de organizaciones mitad criminales y mitad políticas, zonas que sirven de refugio y santuario de organizaciones criminales, y zonas en las que el Estado es incapaz de imponer su autoridad.

En pocas palabras, en estas zonas "el Estado burocrático puede estar presente en la forma de edificios y agentes públicos financiados por el presupuesto nacional, pero la legalidad estatal está ausente: cualquiera que sea el sistema de normas existente es aplicado intermitentemente, en el mejor de los casos" (O’Donnell, 2004, p. 32).

\section{Geografía y presencia territorial del Estado colombiano}

Las siguientes son algunas situaciones de orden social y político que se han mantenido con diferentes intensidades y matices a lo largo de la historia colombiana.

El Estado nunca ha controlado los monopolios clásicos, que, se supone, son la pretensión estatal en cualquier sociedad: violencia, dominio territorial, justicia y tributación. Peter Waldmann (1997) describe esta situación de la siguiente manera:

Si bien en casi ningún país latinoamericano el Estado ha logrado imponer el monopolio de la coacción hasta en sus últimas consecuencias, en Colombia la crisis de autoridad y de legitimidad estatales han ido agravándose periódicamente hasta causar una verdadera disolución del Estado (p. 37).

Durante su existencia como república, se ha presentado una recurrente presencia de la violencia con motivaciones políticas por parte de distintos actores sociales. La persistencia histórica de la violencia ha sido considerada como la principal amenaza a la estabilidad del país (Vargas, 
2003). Durante el siglo pasado, en tres oportunidades la violencia irrumpió con fuerza en la esfera política: primero fue la guerra de los Mil Días (1899-1902); luego, en la década de los cuarenta, el asesinato del candidato presidencial por el Partido Liberal Jorge Eliécer Gaitán, que dio inicio a la violencia liberal-conservadora (1948-1958); a la que siguió, finalmente, la violencia revolucionaria y contrarrevolucionaria asumida por las organizaciones insurgentes, paramilitares y las fuerzas militares oficiales respectivamente (1964-2014).

A pesar de la sistemática utilización de la violencia por parte de actores políticos y civiles, ha habido respeto a los periodos institucionales de los gobernantes. Durante el siglo xx ocurrió sólo un golpe militar, en 1953, relativamente consentido por las élites políticas (Tirado, 1989).

Pero una característica fundamental a la hora de definir o tratar de describir el Estado colombiano es que éste, históricamente, ha mantenido una presencia diferenciada en el territorio nacional; es decir, la continuidad del Estado colombiano ha sido fragmentada, ya que mientras ha logrado integrar los centros urbanos, vastas zonas periféricas del mismo se encuentran excluidas y marginadas de sus servicios básicos. Las razones de dicha fragmentación estarían, en parte, en la compleja geografía del país. Según el Índice de Fragmentación Geográfica que elabora el Centro para el Desarrollo Internacional de la Universidad de Harvard, Colombia ocupa el tercer lugar en este sentido, entre 155 países analizados (Pizarro, 2004).

Colombia se encuentra situada en el corazón de la zona tropical; es atravesada por tres grandes cordilleras (oriental, central y occidental) que alteran su climatología, formando un variado abanico de climas de altura, en sus partes altas, climas cálidos en los valles de sus grandes ríos (Magdalena y Cauca), climas frescos en las partes medias o laderas cordilleranas, climas fríos muy aptos para el desarrollo de la agricultura y el asentamiento de grandes grupos humanos en las mesetas altas, como la Sabana de Bogotá, centro de su desarrollo histórico y actual capital administrativa del país. En lo geopolítico, la complejidad no disminuye, ya que Colombia es a la vez un país andino, caribeño, pacífico y amazónico. Precisamente ha sido esta compleja geografía la que históricamente ha dificultado las comunicaciones e interacciones regionales, afectando gravemente el desarrollo simétrico o uniforme del país. 
Una explicación a dicha situación se encuentra al revisar su proceso de desarrollo demográfico durante el periodo colonial y los inicios del siglo xix. Durante todo este tiempo, el poblamiento se hizo desde el centro (zona andina) hacia las periferias, esto porque en dicha zona se ubicaba el grueso de su población indígena, lo que significaba abundante mano de obra para la explotación de los nuevos territorios y zonas agrícolas. En estas nuevas zonas se establecieron encomiendas y resguardos que fueron generando estructuras bimodales de tenencia de la tierra: latifundios y minifundios. En este último, trabaja la familia campesina en pleno, presentando un relativo excedente de mano de obra con respecto de otros factores de producción. Lo contrario ocurre en el latifundio, ya que en éste se utiliza poca mano de obra, porque su uso de la tierra es extensivo, produciendo un excedente de población rural que por lo general termina migrando a los centros urbanos, produciendo destacamentos de desocupados, que son utilizados en la colonización de nuevas "áreas de frontera agraria" (PNUD, 2004).

En la misma línea, Gouesset (1998) afirma que la migración hacia estas nuevas áreas es por lo general compleja y, dependiendo del contexto, se realiza directamente o por fases, mediadas estas últimas por variables que permean los procesos de atracción o expulsión. La inexistencia de una reforma agraria y la proliferación de tierras baldías hicieron que la colonización se convirtiera en una forma de liberar presiones demográficas y dilatar reformas sociales en el centro. La generalidad en los procesos de colonización campesina ocurridos en Colombia es su espontaneidad, ya que en ellos no ha habido mediación o participación estatal.

Un rasgo característico de estas zonas de fronteras internas es la ausencia estatal. En este sentido, autores como González (2014), Schelenker e Iturralde (2006), Serje (2005), Salazar y Castillo (2001), Soto (2001), Rangel (1999) y Medina (1994) coinciden en que el Estado colombiano históricamente ha mantenido una presencia diferenciada en el territorio nacional. En este trabajo entenderemos presencia estatal como el cumplimiento permanente de las obligaciones primarias del Estado, tales como: impartir justicia, brindar seguridad y garantizar la prestación y el acceso a servicios públicos básicos a todos sus ciudadanos. Si bien esta definición se presenta como poco elaborada, lo que se busca destacar es que la presencia del Estado no sólo se limita a la instalación física de sus instituciones, 
sino que además estas instituciones deben prestar las funciones para las cuales fueron concebidas.

En otras palabras, la continuidad del Estado colombiano ha sido fragmentada, ya que mientras ha logrado integrar a sus dinámicas políticas, jurídicas, económicas y sociales a los centros urbanos, vastas zonas periféricas del mismo se encuentran excluidas y marginadas de sus servicios básicos, posibilitando la aparición y consolidación de poderes paralelos que, basados en la fuerza y el uso de la violencia, imponen órdenes sociales y económicos básicos que permiten la convivencia.

En estas zonas carentes de Estado, las organizaciones paramilitares y guerrilleras se convierten en gérmenes de orden y en la práctica se constituyen como Estados paralelos, pues al quedar todo cubierto con el manto de la ilegalidad, el Estado renuncia a ser garante de las interacciones de los habitantes, dejando los derechos de propiedad, los contratos y los intercambios en una especie de limbo abstracto. Sin ellos no puede haber vida social. Es apenas natural que un nuevo tipo de orden social o Estado primitivo surja en estos contextos.

Estas zonas se terminan configurando como territorialidades armadas, o Estados de guerra, que son definidos por María Teresa Uribe (2001) como espacios del territorio en los que el poder institucional no es soberano y en los que amplios sectores sociales manifiestan la abierta voluntad de no someterse al orden estatal resistiéndose a su control, al dejar latente la posibilidad de confrontarlo con las armas. En los estados de guerra, la violencia se convierte en el medio utilizado para la resolución de las tensiones y los conflictos sociales; es decir, la violencia y quienes la administran o ejercen, pasan a ser el elemento dinamizador del desarrollo de la vida en común.

Cabe resaltar que investigadores como Uribe (1997), Garay (1999) y Gómez (2000) sostienen que la ausencia estatal no se limita sólo a las periferias o áreas de frontera interna, afirmando que en Colombia se vive de manera incierta permanentemente, ya que es un hecho común que cada quien deba negociar la solución específica para cada situación de desorden. En crecientes sectores del centro, como los barrios pobres de las grandes ciudades, impera la ley del más fuerte. 


\section{El lado colombiano de la frontera colombo-brasilera. Generalidades geográficas y económicas}

El panorama antes expuesto es un lugar común en las zonas de fronteras, ${ }^{2}$ conformadas por 11 departamentos y que linealmente cubren $6342 \mathrm{~km}$. La ausencia estatal en estas áreas se ha debido en gran parte a las distancias existentes entre ellas y los "centros políticos y de producción”, ubicados en el interior del país, y a sus características geográficas (zonas selváticas y de difícil acceso con poca o nula infraestructura vial y de servicios). ${ }^{3}$ Estas afirmaciones se sustentan en hechos como que sólo $5.45 \%$ del total de la población colombiana habita en dichas zonas y que sólo hasta 1991 fueron clasificadas como departamentos ${ }^{4}$ (Fundación Seguridad y Democracia, 2008).

La frontera entre Colombia y Brasil tiene una extensión de 1645 kilómetros que corresponden a los departamentos de Amazonas, Guainía y Vaupés en el lado colombiano, y al estado de Amazonas en Brasil. Las más importantes ciudades de la región son Leticia, capital del departamento del Amazonas (Colombia) y su vecina Tabatinga (Brasil). El lado colombiano de la frontera está conformado por cuatro municipios y siete corregimientos departamentales. En el departamento de Amazonas la frontera cruza desde el municipio de Leticia, en el extremo sur del país, hasta los corregimientos de La Pedrera y Tarapacá hacia el norte. En el departamento del Vaupés la línea fronteriza toca el territorio del municipio de Taraira y el corregimiento de Pacoa, Mitú (capital de departamento) y el corregimiento Yavarate, en orden lineal hacia el norte. En el departamento del Guainía, la frontera corta los corregimientos de Pana Pana, Puerto Colombia, San Felipe y La Guadalupe, en el oriente del país, siendo un punto de encuentro de las fronteras de Colombia, Brasil y Venezuela (Sierra, 2003).

\footnotetext{
${ }^{2}$ Para una mayor comprensión sobre el tema de las fronteras internacionales, véase Medina (2006).

${ }^{3}$ Una interesante descripción y caracterización histórica de las fronteras colombianas la realiza Margarita Serje (2005).

${ }^{4}$ En 1995 se aprobó la Ley 191, constituyéndose en el primer marco jurídico para las fronteras colombianas. Los principales objetivos de esta ley fueron: articular las periferias con el centro, favorecer la integración binacional fronteriza y fortalecer la presencia estatal.
} 
Luis Fernando Trejos Rosero / El lado colombiano de la frontera colombo-brasilera

Según la Fundación Seguridad y Democracia (2008), la población distribuida en la frontera es de aproximadamente 91.764 habitantes, es decir, un habitante por cada $1.79 \mathrm{~km}^{2}$. Setenta y cinco por ciento de esta población se concentra en las capitales de los departamentos de Amazonas y Vaupés. La población local es mayoritariamente indígena, aunque en las cabeceras municipales y algunos asentamientos fronterizos hay una presencia activa de colonos llegados del centro del país, dedicados en su mayoría a actividades de minería informal (oro), y al cultivo de hoja de coca y producción de cocaína.

La economía de la región está ligada a las dinámicas del puerto de Leticia sobre el río Amazonas. La economía legal en la zona de frontera es casi inexistente, los cultivos ilícitos han tenido una fuerte incidencia en la economía de Guaviare; mientras que en Guainía la importancia económica gira en torno al proyecto minero aurífero (PNUD, 2004).

Al respecto, Ramírez (2006) sostiene que en esta frontera se han vivido cuatro bonanzas económicas que han alterado sustancialmente las dinámicas ambientales y poblacionales, generando distintos procesos de colonización y violencia. La primera fue la del caucho, que se dio en dos momentos, entre 1890 y 1920, y posteriormente, a mediados de los años cuarenta del siglo pasado, en el marco de la demanda global generada en la posguerra. La segunda fue la de las pieles, entre 1960 y 1970, que acabó las especies nativas y alteró dramáticamente el equilibrio ecológico. La tercera fue la del oro, especialmente en Taraira, a mediados de los ochenta; y la cuarta, la de la coca, que se inició a fines de los ochenta. Estas bonanzas han sido fuente permanente de conflictos entre poblaciones indígenas, colonos, mineros colombianos y brasileños y grupos armados ilegales.

En cuanto a vías de comunicación, la zona de frontera no tiene infraestructura vial que posibilite el desplazamiento terrestre a lo largo de su territorio. Las pocas vías existentes en la región se delimitan a la periferia de la ciudad de Leticia. La marginación estatal de este amplio y estratégico territorio periférico es plasmada en el siguiente texto:

Además del puerto sobre el río Amazonas, la zona fronteriza cuenta con embarcaderos en las poblaciones ubicadas sobre los ríos que corren hacia territorio brasilero, lo que no se traduce en un sistema de vías fluviales que conectan 
el territorio nacional entre sí [...] Esta zona del país, dadas sus características geográficas y la lejanía del centro de poder nacional, mantiene importantes espacios físicos sin presencia del Estado (Fundación Seguridad y Democracia, 2008, p. 3).

\section{Dispositivo militar legal e ilegal}

Esta descripción se confirma al revisar el limitado dispositivo militar y policial desplegado por el Estado colombiano en esta zona de frontera. ${ }^{5}$ Esta limitación se manifiesta, entre otras cosas, porque en Leticia se concentra la mayor cantidad de tropas y esta ciudad sólo se conecta por vía aérea con los demás puestos de frontera. El departamento del Amazonas está bajo jurisdicción de la brigada 26 del ejército con sede en Leticia, adscrita a la sexta división con sede en Florencia Caquetá. Esta brigada cuenta con un batallón de contraguerrilla, uno de selva y uno de servicios, todos ubicados en Leticia. El norte de la frontera es parte del área de operaciones de la brigada 28 de selva, perteneciente a la cuarta división del Ejército Nacional, ubicada en Puerto Carreño (capital del departamento colombiano de Vichada) en la frontera con Venezuela. En esta última ciudad, la Armada Nacional cuenta con un puesto fluvial, que cubre el río Orinoco hasta la frontera con Brasil en La Guadalupe, departamento de Guainía, colindante con la población de Cucuí. En los departamentos de Vaupés y Amazonas, es virtualmente inexistente la presencia de la Armada Nacional. El corregimiento de Tarapacá (departamento de Amazonas) es cubierto por un comando fluvial que se ubica a $1400 \mathrm{~km}$ de distancia, en tanto que los corregimientos de La Pedrera y Taraira no reportan presencia permanente de la Armada. La unidad operativa de la Armada Nacional más importante de la zona, se encuentra en Leticia, y es responsable del control del río Amazonas en el lado colombiano. En el caso de la Fuerza Aérea, esta no cuenta con ninguna unidad aérea en esta frontera. Por último, la Policía Nacional hace presencia en las cabeceras municipales ubicadas sobre la zona de frontera y cuenta con puestos de vigilancia en algunos corregimientos fronterizos. El control migratorio a manos de la

${ }^{5}$ Sobre el dispositivo militar de Brasil en su frontera con Colombia, véase García (2010) y Moreano (2006). 
Luis Fernando Trejos Rosero / El lado colombiano de la frontera colombo-brasilera

Unidad Administrativa de Migración sólo funciona en la ciudad de Leticia (Fundación Seguridad y Democracia, 2008).

En el lado colombiano hacen presencia activa las Fuerzas Armadas Revolucionarias de Colombia-Ejército del Pueblo (FARC-EP) a través de los frentes 1, 16, 29 y 44 entre el Vaupés y Guainía. En el Amazonas se ha reportado la influencia del frente 1 y del frente 63 , así como estructuras paramilitares y de narcotraficantes.

\section{Departamento del Guainía}

El censo realizado por el Departamento Nacional de Estadística (DANE) en 2005, arrojó que la población indígena es mayoritaria en el departamento (64.9\%), principalmente en las zonas rurales de Puerto Colombia, La Guadalupe y Cacahual en las que oscilan entre 98 y 99\%, así como en Barrancominas con $83.9 \%$ y en San Felipe con $84.4 \%$. De ahí que un elevado porcentaje (37\%) de las viviendas en el departamento sean casas indígenas.

Según el Observatorio Presidencial de Derechos Humanos (2010), la agricultura es la principal actividad económica legal del Guainía. Aunque también hay pesca, ganadería y producción de palma de chiquichiqui y el bejuco "Yaré", usada para la fabricación de artesanías. En este sentido, las comunidades indígenas han logrado ciertos grados de organización que les han permitido comercializar sus productos nacional e internacionalmente a través de Artesanías de Colombia, posibilitando mantener el patrimonio cultural de esta población. Si bien el comercio se ha concentrado tradicionalmente en la capital departamental, desde la segunda mitad de la década pasada se han hallado yacimientos de oro y diamantes en la zona denominada El Dorado, cerca de las fronteras con Brasil y Venezuela, y se exploran yacimientos de titanio y uranio en el corregimiento de Puerto Colombia.

En general, la mayoría del territorio del departamento está conformada por resguardos indígenas, siendo los más grandes los de la cuenca media y alta del río Inírida, del bajo río Guainía y Río Negro, ríos Cuiarí e Isana, ríos Atabajo e Inírida y Chorro Bocón, en el Inírida medio. Las etnias más representativas del departamento son la piapoco, sikuani, 


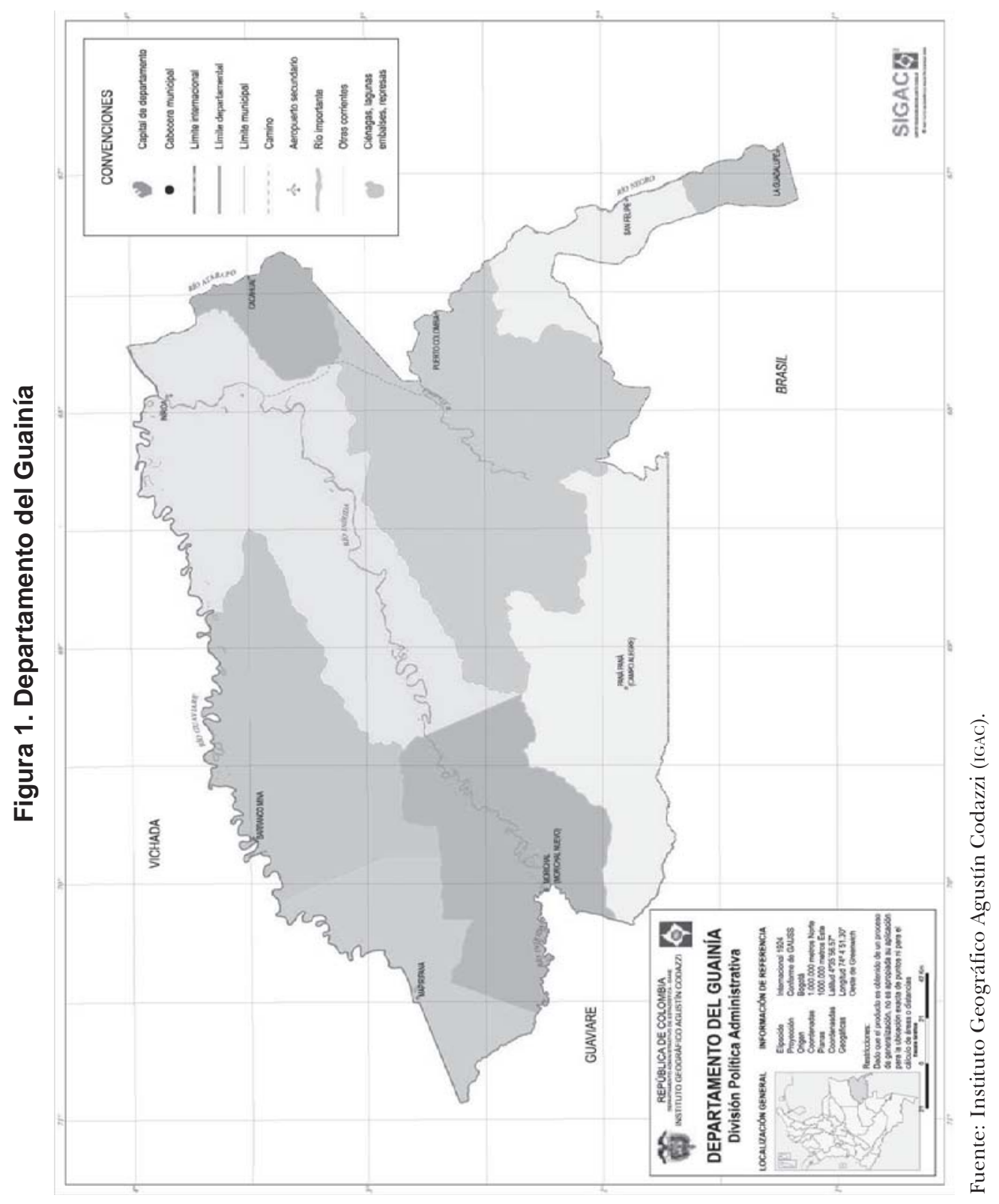


Luis Fernando Trejos Rosero / El lado colombiano de la frontera colombo-brasilera

curripaco y puinave (Observatorio del Programa Presidencial de Derechos Humanos y Derecho Internacional Humanitario [DIH], 2010, p. 4).

\section{Ilegalidad y conflicto armado en el Guainía}

La llegada de las FARC al departamento del Guainía es narrada de la siguiente manera por Alfredo Molano:

Una tarde de enero de 1986 aparecieron en Maimache unos personajes que la gente no tardó en considerar raros. Eran los sobrevivientes de un grupo guerrillero compuesto por seis miembros que venían del Vichada pero que, al pasar por el Guarmiza, fueron sorprendidos por la guardia venezolana, originándose un tiroteo del cual sólo tres lograron escapar [...] Los recién llegados traían armas largas, una notificación suficientemente elocuente, y pronto los habitantes de Maimache incluido el inspector de policía los reconocieron como autoridad. No tardaron en llegar otros muchachos [...] Dieron una charla política y anunciaron las reglas del juego: prohibieron el trago en las minas, el mal uso de las armas cortas, que quedaron confiscadas, la prostitución y sobre todo el robo. La aprobación de la medida fue unánime (Molano, 2005, pp. 76-77).

Con este antecedente, la consolidación de la presencia de las FARC-EP se da por medio del frente 16, adscrito al Bloque Oriental. Bajo el mando de Tomás Medina Caracas (Negro Acacio), logró convertirse en uno de los principales aportantes de recursos financieros del bloque y el secretariado de esta organización. Esto a partir del fortalecimiento del negocio del narcotráfico, aumentando los cultivos ilícitos, el número de laboratorios para el procesamiento de la coca y el aprovechamiento de sus zonas fronterizas para la comercialización de la cocaína; además, este frente tiene a su cargo el ingreso de armas. ${ }^{6}$

${ }^{6}$ Durante los meses de marzo y agosto del año 2000, vía desembarco aéreo, el frente 16 de las FARC-EP recibió en las selvas del sur de Colombia, 10000 fusiles AK-47 de un lote de 50000 que habían negociado en 1999 por un valor que se encuentra entre los 15 y 22 millones de dólares. La operación implicó una compleja logística, que se inició con el embarco de las armas en un avión de carga en Jordania y tuvo escalas en Argelia, Cabo Verde, Granada y Trinidad y Tobago (Trejos, 2012). 
En este momento, el frente 16 se encuentra debilitado por la acción de la fuerza pública; dentro de los golpes recibidos por esta estructura guerrillera, se destacan la captura y detención, el 19 de abril de 2001, en zona rural de Barrancominas (Guainía), del narcotraficante brasileño Luis Fernando da Costa, Fernandinho, a quien este frente le brindaba protección en Colombia. El 2 de septiembre de 2007, en horas de la madrugada, un número indeterminado de soldados del ejército, pilotos de la Fuerza Aérea, marinos de la armada, agentes del Departamento Administrativo de Seguridad y de la policía, desplegaron la operación Sol Naciente que, después de un bombardeo en un campamento ubicado a orillas del río Guaviare, a 130 km de San José, le provocó la muerte a Tomás Medina Caracas (Negro Acacio), máximo comandante de este frente. Tras la muerte de Medina, el mando del frente 16 pasó a manos de Efraín Méndez (Guillermo o Cochornea) y las finanzas del narcotráfico las asumió Géner García Molina (Jhon 40), comandante del frente 43. En este contexto, el ejército, la armada y la policía han ido incrementando su presencia en el departamento (Arias, 2008a).

En la actualidad, el Guainía es epicentro de la explotación ilegal de coltán. Esta nueva bonanza, según García (2012), se inició en 2008, cuando se descubrió que en la tierra negra de este departamento se encuentran mezclados minerales de alto valor para la elaboración de aparatos electrónicos, como columbita, tantalita y tungsteno - los dos primeros son los elementos que componen el coltán. La explotación se lleva a cabo en un lugar llamado Zancudo, en la zona norte del parque nacional natural Puinawai. Revista Semana (2013) aseguró que por medio de fuentes oficiales logró determinar que el frente 16 regula la explotación de la mina ubicada en Zancudo. Este mismo medio periodístico comprobó que llegar a este sitio es casi imposible, por la inexistencia de vías, el río tiene tramos que no son navegables y por aire las guerrillas atacan todo lo que sobrevuele sin su permiso.

La ausencia del Estado y el control territorial del crimen organizado en el Guainía, son descritos magistralmente en la "ruta del coltán":

Transitar la ruta del coltán tiene un precio fijado por varios frentes de las Farc. Cada tonelada que compran en Puinawai cuesta 9 millones de pesos (después del auge minero el precio se estabilizó en nueve mil pesos el kilo), 
Luis Fernando Trejos Rosero / El lado colombiano de la frontera colombo-brasilera

y para sacarla tienen que pagarle cinco millones de pesos al frente Acacio Medina de las Farc. Desde Zancudo los compradores remontan el río Inírida hasta llegar a dos caseríos del departamento del Guaviare: Puerto Flores o Charras. Ahí se encuentran con dos frentes de la guerrilla. El primero es el 44 de las Farc que cobra una vacuna de tres millones de pesos por cada tonelada y después el frente 16 de las Farc que cobra 2 millones. Ya en el Guaviare, los compradores utilizan trochas antiguas de la guerrilla que los llevan hasta San José del Guaviare. Ahí tienen que pagarle un millón de pesos al Frente Séptimo de las Farc, la última columna de este grupo armado que domina la ruta del coltán. En la capital del Guaviare, el control pasa a las manos de los paramilitares, que cobran un peaje de 200 mil pesos por cada tonelada transportada hasta Villavicencio por vía terrestre. Al conquistar la meta, los compradores ya han pagado por una tonelada de coltán más de 20 millones de pesos, sin contar lo que gastan en la logística para transportarlo. Aún así, el negocio sigue siendo jugoso: actualmente en el mercado oficial una tonelada de coltán puede costar más de 50 millones de pesos, una cifra que se eleva en el mercado negro (García, 2012).

\section{Departamento del Vaupés}

La situación socioeconómica del Vaupés es tan preocupante que la presidencia de la República, a través de su programa de derechos humanos, ha manifestado textualmente que:

El departamento también se ha caracterizado por el abandono estatal durante muchos años, lo que se tradujo según el censo de 2005 en un porcentaje de Necesidades Básicas Insatisfechas de $40 \%$ a nivel urbano y $88.1 \%$ a nivel rural, el más alto a nivel nacional (Programa Presidencial de Derechos Humanos y Derecho Internacional Humanitario, 2009a, p. 5).

El panorama institucional en este departamento es tan complejo, que el abastecimiento de gasolina (cuyo precio no es regulado por ninguna autoridad legal) y alimentos de sus habitantes de este departamento depende casi en su totalidad del arribo de aviones de carga desde Villavicencio, que llegan cada 10 días. En cuanto al río Vaupés, éste es navegable entre 
Carurú y Miraflores (capital del departamento de Guaviare), pero el viaje en lancha se demora aproximadamente tres días. El Departamento Administrativo Nacional de Estadística (DANE) estimó la población de Carurú en el año 2005 en 2000 habitantes, de los cuales 641 viven en el casco urbano (Programa Presidencial de Derechos Humanos y Derecho Internacional Humanitario, 2009a).

En el departamento del Vaupés, las FARC-EP hacen presencia a través de la compañía Libardo García, perteneciente al frente 1 (Armando Ríos), actualmente comandado por Reynaldo. Esta unidad guerrillera presenta bajos niveles de confrontación militar ya que está más relacionada con actividades ligadas al procesamiento y comercialización de cocaína, especialmente en la zona rural del municipio de Carurú. También se registran extorsiones a contratistas que realizan obras en las comunidades.

\section{Departamento de Amazonas}

Según el censo efectuado por el DANE en 2005, la población indígena ocupa un importante porcentaje de la población del departamento: 43.4\%, especialmente en el área rural de Mirití-Paraná (100\%), La Chorrera (93.6\%) y Tarapacá (89.6\%). Las actividades económicas legales más desarrolladas en el departamento son el turismo ecológico y la comercialización de artesanías; además hay un activo comercio proveniente de Brasil y Panamá. Asimismo, la pesca es buena en los corregimientos de Puerto Arica, El Encanto y Puerto Alegría, ubicados sobre el río Putumayo (DAne, 2005).

La difícil situación socioeconómica del departamento es retratada por el Programa Presidencial de Derechos Humanos, de la siguiente manera:

El departamento de Amazonas, por su lejanía del centro económico y político del país, presenta unos índices de Necesidades Básicas Insatisfechas algo elevados: $44.1 \%$, sin embargo presenta el mejor panorama entre los antiguos territorios nacionales. Su población total según el mismo censo es de 56.036 personas, 25.004 en el área urbana y 31.032 en el medio rural. El 40\% de la población tiene un nivel académico que alcanza la básica primaria y el $20.7 \%$ la básica secundaria. En materia de acceso a los servicios públicos, el 72.9 de la población se beneficia de la energía eléctrica, el $41 \%$ de un alcantarillado 
Figura 2. Departamento del Vaupés

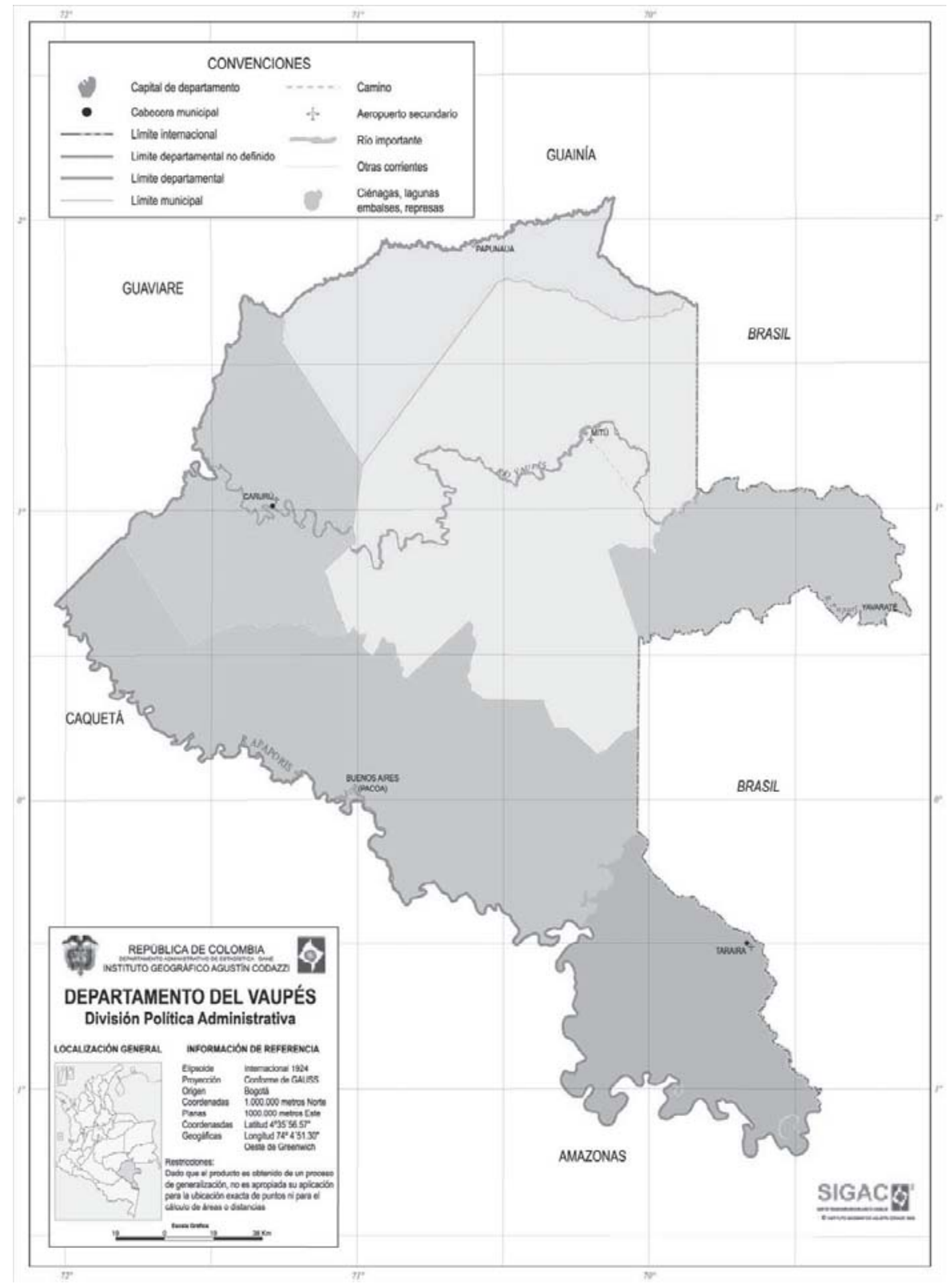

Fuente: Instituto Geográfico Agustín Codazzi. 
y un 54\% tiene acceso al agua potable (Programa Presidencial de Derechos Humanos y Derecho Internacional Humanitario, 2009b, p. 2).

La situación en el departamento de Amazonas no es muy diferente de las anteriores. Su singular orografía selvática y la oportunidad que ofrece de conectarse con tres Estados (Brasil, Perú y Ecuador) por medio del departamento de Putumayo han posibilitado diversos tipos de actividades ilegales; esta situación se ve favorecida porque el departamento es atravesado por cuatro importantes ríos: el Apaporis, el Caquetá, el Putumayo y el Amazonas, y por tener una presencia institucional relativamente precaria. En este departamento la corrupción y el narcotráfico han sido un lugar común desde la década de 1980, momento en el que se convirtió en punto de ingreso de pasta de coca desde Bolivia y Perú. Varios de sus dirigentes políticos han afrontado investigaciones penales o han sido destituidos por la Procuraduría General de la Nación (Arias, 2008b).

\section{Narcotráfico y conflicto armado en la amazonia colombiana}

Las redes internacionales de ilegalidad que se tejen en torno al narcotráfico en esta gran área sin ley o espacio vacío que es el lado colombiano de la frontera colombo-brasilera, son descritas por Reyes (2009), quien plantea que la importancia del Amazonas para el narcotráfico radica en todas las vías fluviales con las que cuenta, ya que muchas directa o indirectamente desembocan en el río Amazonas en Brasil y de ahí salen al resto del mundo (especialmente Europa): a través del Océano Atlántico la cocaína llega hasta algunos países insulares de África Occidental, antiguas colonias portuguesas, tales como las Islas de Cabo Verde y Guinea Bissau y su archipiélago de los Bissagos (Programa Presidencial de Derechos Humanos y Derecho Internacional Humanitario, 2009b).

Es importante destacar que los insumos para el procesamiento de la coca llegan desde Brasil, en cuyo territorio también se encuentran laboratorios de cristalización y puntos de comercialización.

En cuanto a presencia de actores armados ilegales, en los años noventa del siglo pasado se conformó el frente 63 (Rodolfo Tanás). Es importante 
destacar que este frente, al igual que las demás estructuras guerrilleras que operan en esta frontera, no presenta una actividad militar continua, ya que se dedica principalmente a controlar las diferentes etapas de producción y comercialización de cocaína, los corredores de movilidad y la importación de material bélico. Entre 2000 y 2002 hicieron presencia esporádica las Autodefensas del Bloque Sur Putumayo sobre el río del mismo nombre y se registraron casos de extorsión de comerciantes en Leticia.

Sobre la presencia del narcotráfico en el Amazonas, el diario El Colombiano, en su versión digital del día 4 de octubre de 2013, reseña que:

La Oficina de Naciones Unidas contra las Drogas y el Crimen (Unodc) indicó que de 2006 a diciembre de 2012, los cultivos de coca pasaron de 692 a 98 hectáreas sembradas, sobre todo en los límites con Caquetá, Vaupés y Putumayo. De hecho, hoy la mayoría de la coca circulante en Amazonas proviene de los municipios putumayenses Puerto Asís y Puerto Leguízamo [...] Controlar el narcotráfico en esa franja de la frontera es una labor de titanes, basta con decir que dentro del estado brasilero de Amazonas cabe Colombia entera, por su extensión de $15570.745 \mathrm{~km}^{2}$. El pie de fuerza no les alcanza, un drama que comparten con sus colegas peruanos (Matta, 2013).

En este punto del trabajo, es necesario analizar la cambiante y dinámica relación que las FARC-EP han tenido con los cultivadores de coca y el narcotráfico. De su inicial oposición a la siembra de los mismos en 1977, pasan a su aceptación y regulación en 1979, en 1982 inician el cobro de impuestos a los comerciantes de pasta de coca, a los laboratorios de producción de cocaína y a los vuelos de carga. A principios de los noventa inician el regulamiento del comportamiento de los narcotraficantes y miembros de las cocinas. Al respecto, el comandante Julio Rincón, en entrevista concedida durante los diálogos de paz en el Caguán, afirmó que:

El que compraba y vivía en la zona se sometía a las normas de nosotros: no cargar armas, máximo un revólver, jamás una nueve milímetros, no traer gente sin saber uno quién es, y si la traía tenía que responder por lo que él hiciera en la zona (Ferro y Uribe, 2002, p. 99). 


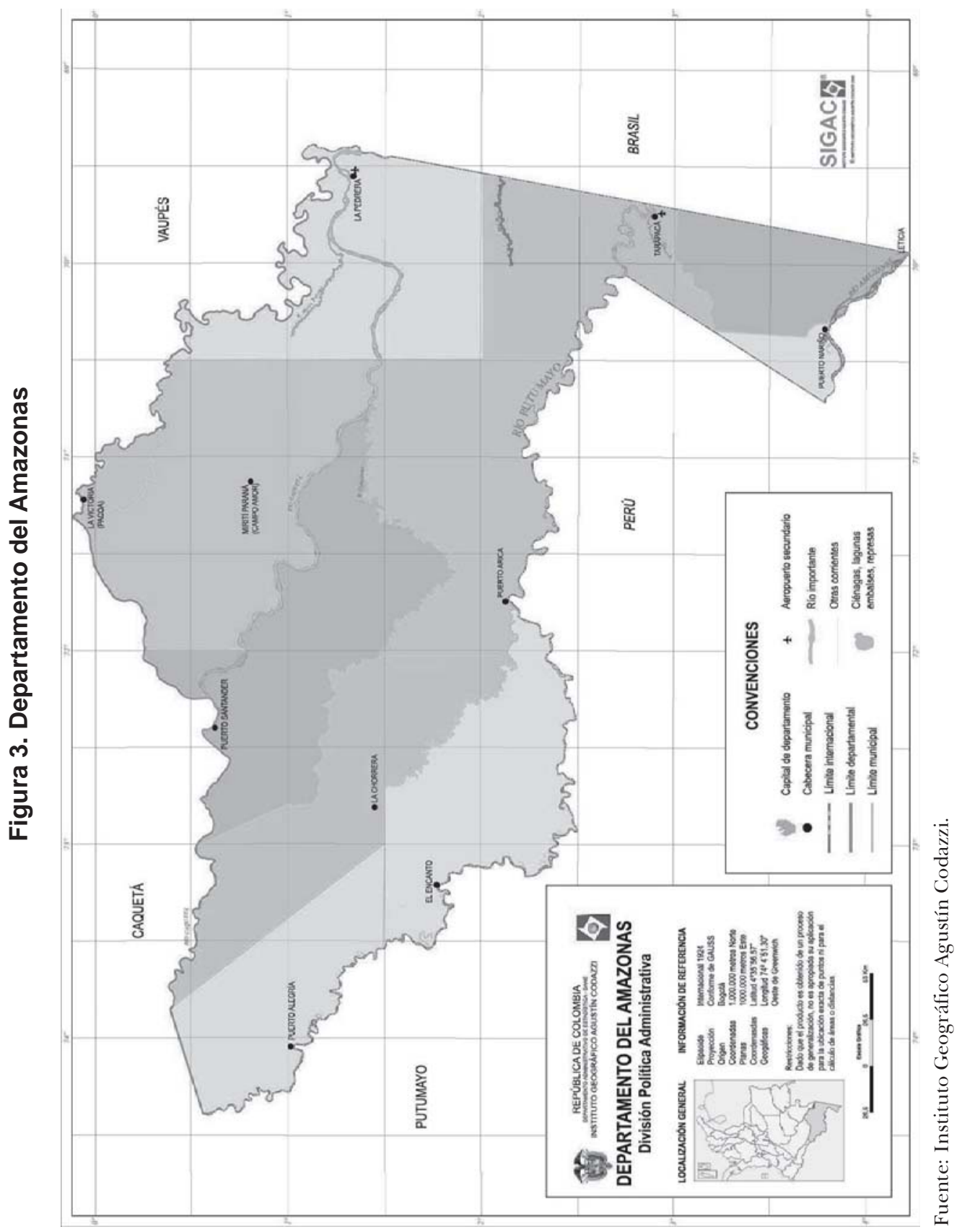


En 1996 organizan las primeras marchas cocaleras contra la fumigación aérea; en 1999 restringen el ingreso de compradores de pasta de coca por temor a la filtración paramilitar y se inicia la competencia por la compra de parte de los paramilitares; y en el año 2000 se inicia la comercialización directa de la pasta de coca por parte de las FARC-EP.

El control y la regulación de la coca en sus territorios también les es funcional orgánicamente, ya que:

Aunque parezca paradójico, el control de la economía de la coca le representa ventajas a la guerrilla en términos de su crecimiento, incluso cuando hay una fuerte reducción de los precios. Las crisis periódicas de la coca también favorecen a la guerrilla porque ingresar a sus filas se convierte casi en la única alternativa frente a la falta generalizada de oportunidades laborales (Ferro y Uribe, 2002, p. 100).

En el plano económico, para Alfredo Rangel (1999) la mitad de los ingresos económicos de las FARC-EP tiene su origen en el narcotráfico, afirmando incluso que esta organización dedica uno de cada tres de sus combatientes a actividades relacionadas directa o indirectamente con el narcotráfico. La realidad indica que esta organización armada tendría serias dificultades para seguir escalando la guerra que libra contra el Estado, sin los importantes recursos económicos que obtiene mediante un complejo sistema de tributación coactiva (gramaje) impuesto en las zonas de cultivos y procesamiento de la hoja de coca.

Lo que debe tenerse claro es que si bien las FARC-EP se relacionan activamente con el narcotráfico, tal y como lo señala Ávila (2008), las FARC-EP no controlan toda la cadena de producción y distribución de la cocaína: en muchos casos su control llega hasta la fase de contacto con quienes intermedian y transportan la cocaína hacia los mercados de consumo final. $\mathrm{Su}$ vínculo y dependencia económica de esta actividad ilegal los obliga a sostener contactos comerciales con narcotraficantes, tal y como quedó demostrado en abril de 2001, cuando en el marco de la "Operación Gato Negro", adelantada por el ejército colombiano en el departamento del Guaviare, contra el frente 16 de las FARC-EP, fue capturado el narcotraficante brasilero Luis Da Costa, alias Fernandinho.

El cuadro 1 grafica lo antes expuesto: 


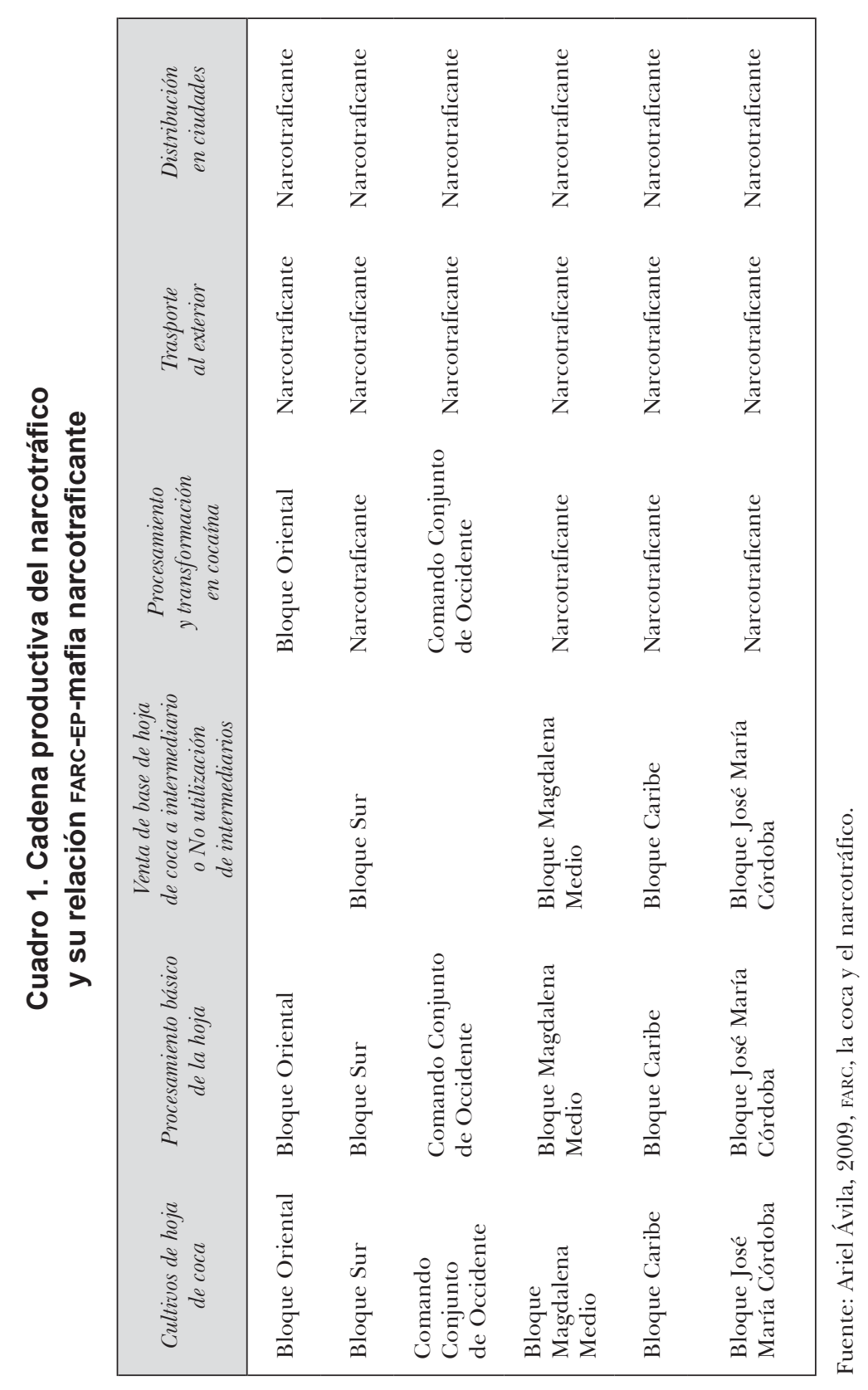


Luis Fernando Trejos Rosero / El lado colombiano de la frontera colombo-brasilera

En las zonas de frontera las FARC-EP controlan algunas rutas por las que sale la cocaína hacia los países vecinos, pero los corredores de ingreso a los grandes mercados de consumidores están en manos de los grandes narcotraficantes y cárteles.

Desde esta perspectiva, las FARC-EP encajan en el concepto de actores transnacionales clandestinos (ATC's), formulado por Peter Andreas (2003), quien los define como:

Actores no estatales que operan a través de las fronteras nacionales violando leyes estatales y quienes apuntan a evadir esfuerzos de vigilancia. Los ATC's son ampliamente variados en sus motivos. Pueden estar motivados por la obtención de lograr altas utilidades y la demanda del mercado, el deseo de llevar a cabo actos de violencia por inspiraciones políticas o religiosas o la búsqueda de empleo y refugio (p. 78).

Este concepto se ha desarrollado dentro de los estudios de seguridad y defensa llevados a cabo en el nuevo escenario internacional, en el que la soberanía y la seguridad territorial no sólo se ven afectadas por variables de tipo militar, sino también por la creciente porosidad de las fronteras en el marco de la globalización.

\section{Conclusiones}

La crítica situación de seguridad y gobernabilidad presente en el lado colombiano de la frontera colombo-brasilera, es fruto entre otras cosas de un Estado centralizado, ausente o débilmente presente en sus periferias. Entendiendo 'presencia estatal' como el cumplimiento permanente de las obligaciones primarias del Estado, tales como: impartir justicia, brindar seguridad y garantizar la prestación y el acceso a servicios públicos básicos a todos sus ciudadanos. Por lo cual no es suficiente la instalación física de sus instituciones, sino que además estas instituciones deben prestar las funciones para las cuales fueron concebidas. Esta ausencia y débil presencia estatal, favorece la aparición y consolidación de grupos armados ilegales que por medio de la violencia construyen órdenes sociales que incentivan 
prácticas económicas ilegales ligadas a redes criminales transnacionales, que tienen como punto de partida las áreas de fronteras.

En el caso colombiano, su conflicto armado interno y la estrategia estatal contrainsurgente, convirtieron las fronteras externas en activas zonas de producción de bienes que escapan al control del Estado y cuya demanda se relaciona con circuitos económicos internacionales. Todo esto, teniendo como telón de fondo la globalización liberal y la creciente porosidad fronteriza de los Estados periféricos que ha afianzado la relación crimen, mercado y Estado (Briscoe, 2008).

La activa presencia de actores armados ilegales, cultivos de coca y laboratorios para la producción de cocaína; la ausencia del Estado en grandes espacios y su poca presencia en las cabeceras municipales, terminan configurando, en el lado colombiano de la frontera colombo-brasilera, una gran área sin ley llena de espacios vacíos, ya que ahí, los actores no estatales vinculados a prácticas y redes ilegales locales e internacionales acumulan tantos recursos e influencia que sobrepasan a las pocas instituciones del Estado, ya sea por ausencia total o por su débil presencia, que en muchos casos se limita a la fuerza pública; es decir, en muchas de estas zonas, las fuerzas militares han pasado a ejercer de hecho el poder político y judicial. Por lo cual el Estado y sus instituciones terminan presentándose en un indivisible marco cívico-militar.

\section{Bibliografía}

Andreas, P. (2003). Redrawing the line. Borders and security in the twenty first century. International Security, 28(2), 78-111.

Arias, A. (2008a). Contexto de violencia y conflicto armado. En C. López (Coord.), Monografía político electoral del departamento de Guainía, 1997 a 2007. Bogotá: Misión de Observación Electoral, Corporación Nuevo Arcoíris, Universidad de los Andes.

Arias, A. (2008b). Contexto de violencia y conflicto armado. En C. López (Coord.), Monografía político electoral del departamento de Amazonas, 1997 a 2007, Bogotá: Misión de Observación Electoral, Corporación Nuevo Arcoíris, Universidad de los Andes.

Ávila, A. (2008). La guerra contra las FARC y las guerras de las FARC. Revista Arcanos, (15), 4-21. 
Luis Fernando Trejos Rosero / El lado colombiano de la frontera colombo-brasilera

Ávila, A. (2009). Las FARC: La coca y el narcotráfico. En C. Medina (Ed.), FARC-EP: Temas y problemas nacionales, 1958-2008 (pp. 173-205). Bogotá: Universidad Nacional de Colombia.

Bartolomé, M. (2003). ¿Áreas sin ley o zonas grises? Análisis de tres casos en la zona noroeste de América del Sur. Ponencia, vi Encuentro de Estudios Estratégicos, Buenos Aires.

Briscoe, I. (2008). Conflictos en la frontera: Las nuevas zonas calientes en América Latina. Fundación para las Relaciones Internacionales y el Diálogo Exterior. Recuperado de: < http://www.fride.org/download/COM_Bordelands_Americas_ ESP_jul08.pdf $>$

Cirino, J. (2003). Las áreas sin ley en el hemisferio: Una hipótesis de trabajo. Red de Seguridad y Defensa de América Latina. Recuperado de: < http://www.resdal. org/Archivo/d000025b.htm>

Cirino, J. y Elizondo, S. (2003). Áreas sin ley: Orígenes del fenómeno y percepciones de amenaza. Ponencia, Santiago, Chile: REDES.

Departamento Nacional de Estadística (2005). Censo General. Recuperado de: $<$ https://www.dane.gov.co/index.php/poblacion-y-registros-vitales/censos/ censo-2005>

Ferro, J. y Uribe, G. (2002). El orden de la guerra. Las FARC-EP entre la organización y la política. Bogotá: Centro Editorial Javeriano.

Fundación Seguridad y Democracia (2008). Colombia: Seguridad y defensa en las fronteras. Revista Coyuntura de Seguridad, (21), 1-23.

Garay, L. (1999). Construcción de nueva sociedad. Bogotá: Tercer Mundo Editores.

García, C. (2012). Viaje al corazón de la minería ilegal en el Guainía. Recuperado de: $<$ http://lasillavacia.com/historia/viaje-al-corazon-de-la-mineria-ilegal-en-guainia-37128>

García, V. (2010). Impactos del crimen transnacional en la región amazónica. En A. Vargas (Ed.), Inseguridad en la región amazónica: Contexto, amenazas y perspectivas. Bogotá: Universidad Nacional de Colombia, uniJus.

Gómez, H. (2000). El lío de Colombia. ¿ Por qué no logramos salir de la crisis? Bogotá: Tercer Mundo Editores.

González, F. (2014). Poder y violencia en Colombia. Bogotá: odecofi, CineP.

Gouesset, V. (1998). El territorio colombiano y sus márgenes. La difícil tarea de la construcción territorial. Territorios. Revista de Estudios Regionales y Urbanos, (1), 77-94.

Guehénno, J. M. (1999). The impact of globalization on strategy. Survival, (40), 5-19.

Lupsha, P. (1993). Gray area. En M. Manwaring (Ed.), Gray Area Phenomena. Confronting the New World Disorder. Boulder: Westview Press.

Maisonneuve, E. (1998). La metamorfosis de la violencia. Ensayo sobre la guerra moderna. Buenos Aires: GEL. 
Matta, N. (2013). Los muertos del Amazonas están ungidos de coca. Recuperado de: <http://www.elcolombiano.com/BancoConocimiento/L/los_muertos_del amazonas_estan_ungidos_de_coca/los_muertos_del_amazonas_estan_ ungidos_de_coca.asp>

Medina, C. (1994). Autodefensas, paramilitares y narcotráfico. Origen, desarrollo y consolidación: El caso de Puerto Boyacá. Bogotá: Documentos Periodísticos.

Medina, E. (2006). Aportaciones para una epistemología de los estudios sobre fronteras internacionales. Estudios Fronterizos, 7(13), 9-27.

Molano, A. (2005). Aguas arriba. Entre la coca y el oro. Bogotá: El Áncora.

Moreano, H. (2006). Las implicaciones del conflicto interno colombiano para las fronteras de Ecuador, Perú, Brasil y Venezuela, 2000-2005. Revista Iconos, (24), 161-170.

Observatorio Programa Presidencial de Derechos Humanos y Derecho Internacional Humanitario (2010). Diagnóstico departamental Guainía. Bogotá: Presidencia de la República.

O'Donnell, G. (2004). Why the rule of law matters. Journal of Democracy, 15(4), $32-47$.

Pizarro, E. (2004). Una democracia asediada. Balance y perspectivas del conflicto armado en Colombia. Bogotá: Grupo Editorial Norma.

Programa de Naciones Unidas para el Desarrollo (2004). El conflicto. Callejón con salida. Informe Nacional de Desarrollo Humano para Colombia, Colombia.

Programa Presidencial de Derechos Humanos y Derecho Internacional Humanitario. (2009a). Diagnóstico departamental Vaupés. Bogotá: Presidencia de la República.

Programa Presidencial de Derechos Humanos y Derecho Internacional Humanitario. (2009b). Diagnóstico departamental Amazonas. Bogotá: Presidencia de la República.

Ramírez, S. (2006). Colombia-Brasil: Distante vecindad se fortalece en la seguridad y el comercio. Revista Análisis Político (58), 3-34.

Rangel, A. (1999). Colombia: Guerra en el fin de siglo. Bogotá: Tercer Mundo Editores.

Revista Semana (2013). La selva herida por la minería. Marzo 29. Recuperado de: <http://www.semana.com/nacion/articulo/la-selva-herida-mineria/338157-3>

Reyes, A. (2009). Guerreros y campesinos. El despojo de la tierra en Colombia. Bogotá: Grupo Editorial Norma.

Salazar, B. y Castillo, M. (2001). La hora de los dinosaurios. Conflicto y depredación en Colombia. Bogotá: cerec-cidse, Universidad del Valle (Colección Sociedad y economía 1).

Serje, M. (2005). El revés de la nación. Bogotá: Ediciones Uniandes.

Schelenker, J. e Iturralde, M. (2006). Uso del discurso de los derechos humanos por los actores armados en Colombia: ¿Humanización del conflicto o estrategia de guerra? Revista Análisis Político, (56), 29-50. 
Luis Fernando Trejos Rosero / El lado colombiano de la frontera colombo-brasilera

Sierra, Á. (2003). Las fronteras de Colombia entre la guerra y el abandono. Revista Colombia Internacional, (57), 150-157.

Soto, A. (2001). Evolución del conflicto interno en Colombia. Ponencia, Center For Hemispheric Defense Studies, Panel Origen, evolución y perspectivas del conflicto interno en Colombia, Washington.

Tirado, Á. (1989). Rojas Pinilla: Del golpe de opinión al exilio. Enciclopedia Nueva Historia de Colombia, t. II. Bogotá: Planeta.

Trejos, L. (2012). Un actor no estatal en el escenario internacional. El caso de las FARC-EP, 1964-2010. Tesis doctoral. Santiago de Chile: Instituto de Estudios Avanzados de la Universidad Santiago de Chile.

Uribe, M. (1997). La negociación de los conflictos en el ámbito de nuevas y viejas sociabilidades. Conflicto y contexto. Resolución alternativa de conflictos y contexto social. Bogotá: Tercer Mundo Editores, Instituto sER de Investigaciones, Colciencias.

Uribe, M. (2001). Nación, ciudadano y soberano. Medellín: Corporación Región.

Vargas, A. (2010). Seguridad democrática, conflicto interno armado y su regionalización. En A. Vargas (Ed.), Seguridad en democracia: Un reto a la violencia en América Latina (Colección Grupos de Trabajo). Buenos Aires: Clacso.

Wanderley, F. (2000). Atualidade mundial e desafios brasileiros. Estudos Avancaos Universidad de Sao Paulo, (39), 21-43.

Waldmann, P. (1997). Cotidianización de la violencia: El ejemplo de Colombia. Análisis Político, (32), 33-51. 